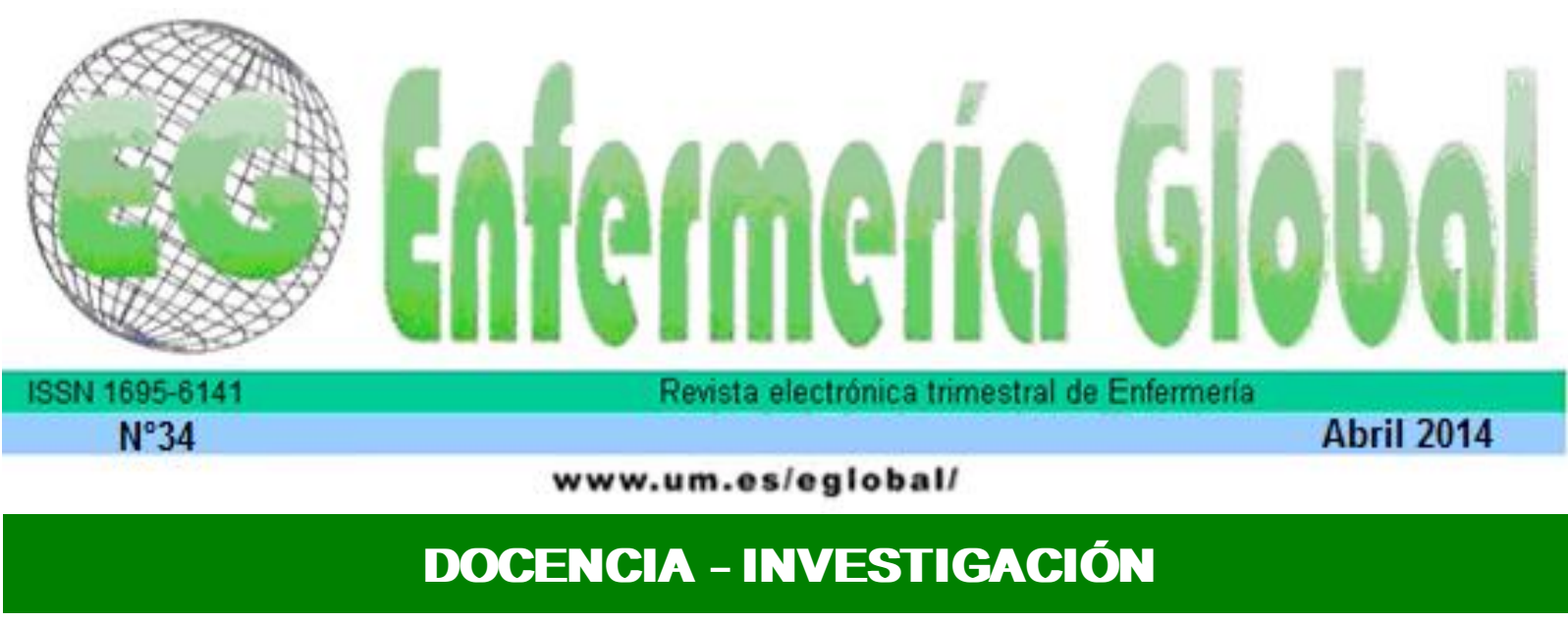

\title{
Web Site de Insuficiencia Cardiaca como propuesta de educación en salud
}

Web Site de Insuficiência Cardíaca como proposta de educação em saúde

Welosite of heart failure as a proposal of education for health

\section{*Dantas Cavalcanti, Ana Carla **Manso, Carla dos Reis *de Carvalho Queluci, Gisella **Alves da Silva, Vanessa ${ }^{* * *}$ da Silva Correia, Dayse Mary ${ }^{* * * *}$ Andrade Martins, Wolney **do Amaral Almeida, Brenda}

*Doctora en Enfermería, Profesora Adjunta de la Escuela de Enfermería Aurora de Afonso e Costa de la Universidad Federal Fluminense/ EEAAC/UFF. E-mail: anacarladc@yahoo.com.br **Enfermera. ${ }^{* * *}$ Doctoranda en Ciencias Cardiovasculares. Profesora Asistente de la / EEAAC/UFF. **** Doctor en Ciencias, Profesor adjunto de la Facultad de Medicina de la Universidad Federal Fluminense.Brasil.

Palabras clave: insuficiencia cardiaca; cuidados de enfermería; sitio. Palavras chave: insuficiência cardiaca; cuidados de enfermagem; site. Keywords: heart failure; nursing care, site.

\section{RESUMEN}

Es un estudio que propone como alternativa de intervención de enfermería la creación de un sitio web, con informaciones educativas para pacientes con insuficiencia cardiaca.

Tuvo como objetivos específicos describir el proceso de la creación del sitio de web y validar el contenido por profesionales de la salud y pacientes.

Para esto, utilizó una metodología descriptiva con abordaje cualitativo dividido en tres fases: definición del contenido, estructuración y validación del sitio web.

El resultado general de las evaluaciones de los profesionales del área de la salud demostró la puntuación media de $51,25(93,18 \%)$ y para los pacientes la puntuación media fue de $44,25(98,33 \%)$. Por lo tanto, fue clasificada como bien elaborada y logró los objetivos propuestos.

Se puede concluir que el sitio web es una alternativa de intervención para aumentar la adhesión al tratamiento y mejorar la calidad de vida de pacientes con insuficiencia cardiaca. Así, podrán reducirse las hospitalizaciones y posibles complicaciones derivadas de la insuficiencia cardiaca a través de la difusión de las informaciones y en la educación de la población. 


\section{RESUMO}

Trata-se de uma pesquisa que propôs como alternativa de intervenção de enfermagem a criação de um web site, com informações educativas para pacientes com Insuficiência Cardíaca. Teve como objetivos específicos descrever o processo de criação do web site e validar o conteúdo por profissionais de saúde e pacientes. Para isso, utilizou metodologia descritiva com abordagem qualitativa dividida em 3 fases: definição do conteúdo, estruturação e validação do web site. 0 resultado geral das avaliações dos profissionais da área de saúde demonstrou o escore médio de $51,25(93,18 \%)$ e para os pacientes o escore médio foi de 44,25 (98,33\%). Portanto, foi classificado como bem elaborado e atingiu os objetivos propostos. Conclui-se que o site é uma alternativa de intervenção para aumentar a adesão ao tratamento e melhorar a qualidade de vida de pacientes com insuficiência cardíaca. Assim, poderá reduzir as internações e possíveis complicações decorrentes da insuficiência cardíaca através da difusão das informações e na educação da população.

\section{ABSTRACT}

It is a study that proposes as an alternative of intervention of nursing the creation of a website, with educative information to heart failure patients.

Objectives: To describe the process of the creation of the website and to validate the content by health professionals and patients.

It was carried out a descriptive methodology with qualitative boarding divided in three phases: definition of content, structure and validation of the website.

The general result of the evaluation of the professionals in the field of health showed the average score of $51.25(93.18 \%)$, and for the patients the average score was $44.25(98.33 \%)$. Therefore, it was classified as well elaborated and it achieved the proposed objectives.

To conclude, it can be said that the website in an alternative of intervention to increase the acceptance of the treatment and to improve the quality of life of heart failure patients. In this way, the hospitalizations and the possible complications from the heart failure could be reduced through the diffusion of the information and the education of the population.

\section{INTRODUCCIÓN}

El avance tecnológico y la difusión de Internet han permitido que las informaciones sean cada vez más accesibles a todas las clases sociales. La búsqueda de información sobre los más variados asuntos es lo que motiva a la mayoría de las personas a utilizar esta red mundial ${ }^{1}$.

Para algunos autores Internet es una excelente herramienta en el desarrollo y perfeccionamiento de diversas profesiones de salud. Cabe resaltar que en lo que respecta a Enfermería, la informática y sus saltos evolutivos tecnológicos han contribuido a la actuación de los enfermeros utilizando estos recursos en diversos escenarios, desde el campo intrahospitalario a la atención ambulatorial a la comunidad $^{1,2}$.

En este sentido, vale destacar que la educación en salud es un item importante en las actividades de enfermería, y está ganando importancia en el ámbito de esta Era interactiva virtual, pudiendo resultar beneficiosa para los pacientes, específicamente, los diagnosticados con insuficiencia cardiaca y los profesionales especialistas en el área.

Así, el objeto de este estudio fue la web site como método de enseñanza para pacientes con insuficiencia cardiaca. Los objetivos fueron: describir el proceso de 
creación del web site y validar el contenido. Cabe señalar que el uso de Internet como medio de promover la educación en salud aún es un desafío para la realidad brasileña. Como esta tecnología ha sido poco explorada por la enfermería, se hace necesario acompañar y participar de los cambios a fin de contribuir a ampliar nuestro campo de actuación, así como mejorar la calidad del acceso a las informaciones de salud.

\section{ABORDAJE METODOLÓGICO}

Conforme a lo instituido en la resolución n 196/96 del Consejo Nacional de Salud (CNS), esta investigación fue sometida y aprobada por el Comité de Ética e Investigación (CEP) del Hospital Universitario Antônio Pedro, número de aprobación 174/2010 / CAAE no 0139.0.258.000-10.

La metodología utilizada en esta investigación fue de tipo descriptivo que "tiene como propósito observar, describir, explorar, clasificar e interpretar aspectos de hechos o fenómenos" ${ }^{3}$. El enfoque fue de naturaleza cualitativa, o sea, aquella investigación que "no se preocupa en enumerar las veces en que una variable aparece y sí lo que ellas presentan, intentando comprender en la visión de los sujetos participantes un problema que vivencian y se considera en el contexto social en que ocurre el evento",

La colecta de datos tuvo lugar mediante las siguientes fases:

\section{a) Fase 1: Definición del contenido}

Tratándose de un Web site de difusión de informaciones que aborda temáticas referentes a la prevención y promoción de la salud sobre la insuficiencia cardiaca, su creación se basó en las directrices brasileñas, americanas, europeas, además de la $\mathrm{NIC}$-clasificación de las intervencions de enfermería- que se encuadra en el dominio comportamental, cuya clase es educación del paciente y la intervención se refiere a la emseñanza: proceso de enfermedad. También se realizó consulta sistemática en la base de datos LILACS, MEDLINE, con descriptores en portugués e inglés, tales como: Insuficiencia Cardiaca (Heart Failure), Enfermería (Nursing), Educación (Education) atendiendo a publicaciones dentro de la temática escogida.

Al reunir los artículos y materiales de interés para la elaboración del web site, fue hecha la definición del contenido de informaciones capaz de auxiliar en la prevención y promoción de la salud referente a la insuficiencia cardiaca. De esta forma, las informaciones que componen el contenido son: introducción; definición de insuficiencia cardiaca; qué alteraciones causa la insuficiencia cardiaca al corazón; cómo se desarrolla; principales causas; señales y síntomas; descompensación cardiaca; diagnóstico; exámenes complementarios; tratamiento no farmacológico; tratamiento quirúrgico; informaciones sobre el Grupo Corazón Fuerte del Hospital Universitario Antônio Pedro (HUAP); declaraciones de los integrantes del grupo; informaciones sobre el GESAE_IC - Grupo de Sistematización de Asistencia de Enfermería en Insuficiencia Cardiaca - ; Clínicas de Insuficiencia Cardiaca; resultados de investigación; recetas saludables; juegos educativos, links útiles y creación de una estructura de soporte para responder eventuales dudas y sugerencias de los usuarios. 
Esta fase se refiere a la creación, estructuración y teste del web site. En esta fase, se escogieron el logotipo, layout, color, forma de presentación, links, tipos de juegos e imágenes. Para su creación fueron necesarios conocimientos generales de informática, edición de páginas web, además de recursos materiales como: recursos de hardware, periféricos y recursos de software.

El web site está compuesto de diecinueve páginas, distribuidas en quince secciones de contenido temático. La página inicial (home page) consta de un archivo Index.html con animación en Flash, siendo editado en bloc de notas, lo que resultó en un archivo de 1 Kilobyte (Kb). Los juegos educativos, de memoria y ahorcado, fueron organizados en Macromedia Flash MX 2004. El contenido fue estructurado en forma de archivos HTML. En la medida en que fueron definidos, fueron editados en el Bloc de Notas. Concomitantemente, se seleccionaron las imágenes para la ilustración del contenido. Estas imágenes adquiridas en una carpeta del disco duro en formato JPG, usándose para esto el software Microsoft Office Picture Manager. En el recurso de hardware se utilizó un computador con procesador Pentium Dual ${ }^{\circledR} 1.6 \mathrm{MHz}$ con $1 \mathrm{~Gb}$ de memoria Ram y disco duro de $150 \mathrm{~Gb}$ de capacidad de almacenamiento. El sistema operacional fue Windows 7 de Microsoft Corporation ${ }^{\circledR}$. Y relacionados con el software se utilizó: Editor de texto - Bloc de notas; Editor de página Web - Bloc de notas; Editores de Imagen - Fueron adoptados los softwares Microsoft Office Manager ${ }^{\circledR}$, Corel Draw X3 versión 13. Navegadores - Para el test de las páginas en ambiente de Internet, se seleccionaron los softwares Internet Explorer $6.0 \mathrm{~d}$ Microsoft Corporation ${ }^{\circledR}$.

\section{c) Fase 03: Validación del Web site}

Esta fase contempló la validación del Web site. El criterio de inclusión de los peritos fue: tener especialidad en cardiología, máster o doctorado, y/o actuar en algún proyecto en esta temática (médicos y enfermeros), además de trabajar un mínimo de cinco años en la especialidad y para los pacientes fue tener insuficiencia cardiaca y frecuentar las reuniones del grupo Corazón Fuerte. Durante el proceso de validación, fueron seleccionados los profesionales de salud y pacientes que cumplimentaron todos los criterios de inclusión del estudio. Los peritos, que formaron parte de la investigación, trabajan en el ambulatorio de cardiología, en proyectos de insuficiencia cardiaca, en el Hospital Universitario Antonio Pedro (HUAP-UFF). En total, fueron ocho evauadores, siendo cuatro peritos (profesionales de salud) y cuatro pacientes.

\section{Organización y análisis de las informaciones}

El web site fue una alternativa de intervención basado en las directrices nacionales, americanas y europeas, y también en la NIC, en la medida que disponibiliza informaciones sobre la promoción, prevención, además de orientaciones para mejorar la calidad de vida de los individuos que viven con insuficiencia cardiaca.

Además, estuvo compuesto por módulos e imágenes ilustrativas con la intención de facilitar la comprensión, despertar el interés, estimular el acceso y divulgar las informaciones sobre la insuficiencia cardiaca, con las respectivas orientaciones, estimulando el manejo adecuado a fin de evitar complicaciones. En la medida en que los contenidos fueron definidos, los mismos fueron editados y, concomitantemente, se seleccionaron las imágenes para la ilustración del contenido. 
Los demás atributos que componen el concepto del Web site están relacionados con la facilidad de entendimiento, navegación, adecuación de las imágenes y de las informaciones y disponibilización de links externos relacionados con el contenido temático del trabajo.

Se adoptaron dos instrumentos de evaluación. El primero, aplicado a los profesionales de salud, y el segundo a los pacientes. Para cada item, de cada criterio, el evaluador concede un concepto de acuerdo con las siguientes posibilidades: excelente (5), muy bien (4), bien (3), regular (2), malo (1) y pobre (0). Al final se obtuvo un escore que indicó la calidad del web site, de acuerdo con las evaluaciones.

En el primer instrumento, sometido a los profesionales de salud, los criterios fueron los siguientes:

Contenido general de las informaciones. Se refiere a la conformidad de las informaciones disponibilizadas y a la relación con los objetivos propuestos. Evalúa la claridad y organización de las informaciones para que no haya errores de interpretación por los usuarios.

Presentación de las informaciones. En este criterio se evaluó el diseño de las páginas, las imágenes para ilustrar cada asunto, facilidad de navegación y la organización de las informaciones.

El segundo instrumento de validación, aplicado a los pacientes, tuvo los mismos criterios, con algunas adaptaciones en los items, privilegiando la forma de presentación del site, imágenes, facilidad de navegación y didáctica do web site.

Para el instrumento de validación aplicado a los profesionales de salud, la puntuación máxima fue de 55 puntos y para los pacientes fue de 45 puntos.

A partir de las respuestas obtenidas en los cuestionarios de validación (fase 3), relacionadas con el contenido y estruturación del web site, fue hecha la organización de los datos y análisis cualitativo, para la comprensión de estos dados aprendidos y una percepción de las manifestaciones ${ }^{4}$.

El análisis se refiere a los datos de la validación de los dos instrumentos. Cada instrumento fue analizado separadamente. Para cada instrumento aplicado a los profesionales de salud (grupo I) se hizo el siguiente análisis:

- De cero a 11 puntos. Las informaciones contenidas en el Web site no contribuyen a que los objetivos propuestos sean alcanzados.

- De 12 a 22 puntos. A pesar de la utilidad de las informaciones, su contribución en el alcance de los objetivos deberá ser complementada con material adicional de fuera del Web site;

- De 23 a 33 puntos - El usuario precisará de una guía mejor estructurada para alcanzar los objetivos establecidos. Una lista de favoritos para páginas o Web sites específicos, puede ser aconsejable; 
- De 34 a 44 puntos. El Web site contiene buenas informaciones, mas necesita de un mapa con direcionamiento específico para ayudar a los usuarios a encontrar ciertas informaciones;

- De 45 a 55 puntos. El resultado clasifica el Web site como bien elaborado, y así alcanza los objetivos propuestos.

El resultado de la validación del instrumento aplicado a los pacientes (grupo II) tuvo el siguiente análisis:

- De cero a 9 puntos. Las informacione contenidas en el Web site no contribuyen a que los objetivos propuestos sean alcanzados.

- De 10 a 18 puntos. A pesar de la utilidad de las informaciones del Web site, su contribución en el logro de los objetivos deberá ser complementada con material adicional fuera del Web site.

- De 19 a 27 puntos. El usuario precisará de una guía mejor estructurada para alcanzar los objetivos establecidos. Es aconsejable una lista de favoritos para páginas específicas.

- De 28 a 36 puntos. El Web site contiene buenas informaciones, mas necesita de un mapa con direcionamiento específico para ayudar a los usuarios a encontrar ciertas informaciones.

- De 37 a 45 puntos, el resultado clasifica el Web site como bien elaborado, y así alcanza los objetivos propuestos.

Los escores totales (Et) obtenidos en todas las evaluaciones se sometieron a la determinación de la media aritmética. Para la aprobación del Web site, en el Grupo I se estableció un valor mínimo a ser alcançado en las validaciones. Este valor tuvo que ser superior al encontrado en el límite inferior de la franja de 45 a 55 puntos, o sea, 0,82 del escore máximo (55), que representa 45 puntos, por tanto el límite de seguridad (LS). De la misma forma, para el Grupo II, este valor quedó establecido en 37 puntos. En este caso, para que el Web site sea considerado como adecuado a los objetivos para los que fue designado, la media de los escores totales de las evaluaciones precisó ser superior al valor establecido como LS para cada grupo.

Para la localización de puntos donde el Web site precisó ser reevalaudo, se adoptó el siguiente análisis: el valor esperado para la media de los escores por item (Ei) equivale a 0,82 del valor del escore máximo (5), o sea, para el Grupo I, este valor fue 4,1 y para el Grupo II, también fue de 4,1. Tras la validación, el Web site fue actualizado y corregido.

\section{RESULTADOS Y ANÁLISIS DE DATOS}

Los instrumentos de validación fueron aplicados a los profesionaless del área de salud (grupo I) y pacientes con insuficiencia cardiaca que frecuentan el grupo Corazón Fuerte (grupo II) en el Hospital Universitario Antônio Pedro. Las variables relacionadas con el proceso de validación se refieren al perfil de los evaluadores, que incluyen: edad, género y profesión, para los dos grupos. En el grupo I, de los 
profesionales de salud, hubo un aumento de la especialidad y tiempo de actuación. Y en el grupo II, de los pacientes, el aumento fue de escolaridad y del tiempo de diagnóstico de la insuficiencia cardiaca. Los instrumentos incluyen los criterios del protocolo del estudio.

La edad de los evaluadores varió de 29 a 57 años, siendo la faja etaria de 50 a 57años, la que presentó mayor frecuencia (Tabla I).

Tabla I. Frecuencia por faja etaria de los evaluadores del Web site.

\begin{tabular}{lccccc}
\hline FE & $29-\mid 36$ & $36-\mid 43$ & $43-\mid 50$ & $50-\mid 57$ & Total \\
AVA & & & & & \\
Peritos & 2 & 1 & 1 & 0 & 4 \\
Pacientes & 0 & 0 & 0 & 4 & 4 \\
Total & 2 & 1 & 1 & 4 & 8 \\
\hline
\end{tabular}

${ }^{\star} \mathrm{FE}=$ faja etaria; $\mathrm{AVA}=$ evaluadores.

Entre los evaluadores del área de salud (Grupo I) hubo predominio de participantes del género femenino (75\%) y en el grupo de los evaluadores formado por pacientes (Grupo II) no hubo predominio, correspondieron al género femenino (50\%) y al masculino (50\%).

Los evaluadores del web site fueron tres enferneras, un médico, cuatro pacientes, totalizando ocho evaluadores.

En cuanto a la profesión, en el grupo de los evaluadores del área de salud, de los cuatro participantes, tres son enfermeras (dos doctoras y una doctoranda) y uno es médico (doctor). Todos son docentes, especialistas en cardiología y el tiempo de actuación varía de 6 a 20 años. El grupo II, de los pacientes, estuvo compuesto por auxiliar de servicios generales, electricista, albañil y ama de casa.

En cuanto al tiempo de diagnóstico de insuficiencia cardiaca, referente a los pacientes que evaluaron el web site, hubo variación entre 4 y 11 años. De acuerdo con la clasificación funcional de la New York Heart Association (NYHA), los pacientes que evaluaron el web site, están en la clase II, que se refiere a la limitación discreta de las actividades de la vida diaria, ausencia de síntomas en reposo, y aumentados en la actividad física, pudiendo ser auscultados estertores bibasais, soplo y tercer ruido cardiaco. En cuanto al nivel, ellos están en el nivel $\mathrm{C}$ de la Clasificación de la American College of Cardiologists/American Heart Association, que engloba pacientes con lesión estructural cardíaca y síntomas de insuficiencia cardíaca ${ }^{5}$.

\section{Validación de los profesionales del área de la salud}

Los datos de la validación hecha por los cuatro profesionales del área de salud (Grupo I) están relacionados con el contenido del web site. Ellos se refieren a los criterios de contenido general y a la forma de presentación de las informaciones. El resultado general de las evaluaciones de los profesionales del área de la salud (Gráfico I) demostró el escore medio de 51,25 (93,18\%) de los 55 esperados. Por tanto, clasifica el web site como bien elaborado y alcanzó los objetivos propuestos. 
Gráfico I. Evaluaciones de los profesionales del área de la salud (Grupo I)

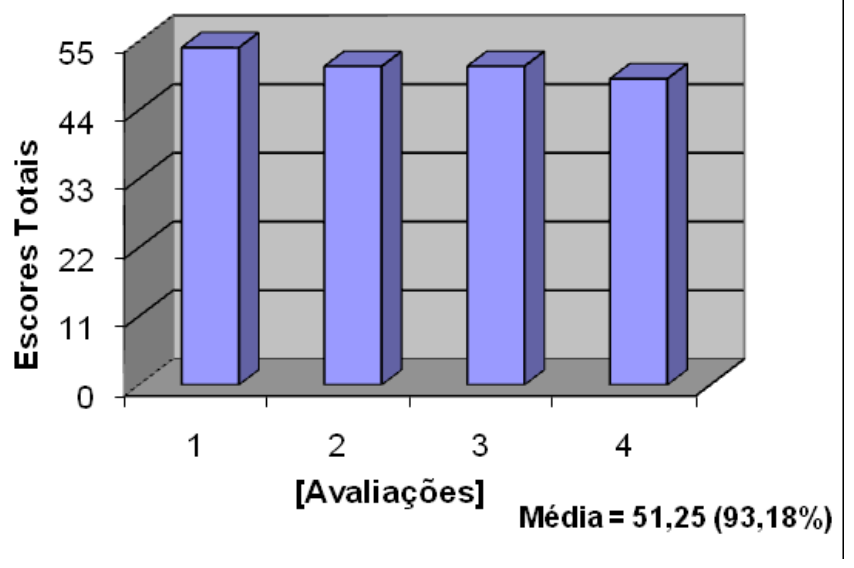

El análisis de los datos del grupo de los profesionales de salud alcanzó escores por encima del LSEt (o igual a 45puntos).

En el análisis de cada escore en los items de los criterios, se estipuló un escore mínimo. En ese análisis, el escore máximo fue de cinco (5) puntos, si fuese alcanzado en todos los 11 items alcanzaría el escore total de 55 puntos. El LS (0.82) representa, entonces, el valor 4,1. Esto significó que en cada item, el valor medio esperado de las evaluaciones debería estar por encima de este valor, estipulado como el límite de seguridad (LSEi) del escore por item (Tabla II).

Tabla II. Escores medios de los items de la validación de los profesionales del área de la salud y los desvíos del Límite de Seguridad (LSEi=4,1).

\begin{tabular}{l|lcc}
\hline Criterios & Items & $\boldsymbol{X}$ & $\boldsymbol{D} \boldsymbol{V}$ \\
\hline Contenido & $\begin{array}{l}\text { 1a. El web site disponibiliza informaciones } \\
\text { de acuerdo con los objetivos especificados } \\
\text { previamente. }\end{array}$ & 4,50 & $+0,40$ \\
& $\begin{array}{l}\text { 1b. Las informaciones están claramente } \\
\text { indicadas y organizadas a fin de ser } \\
\text { entendidas por los 121 usuarios. }\end{array}$ & 5,00 & $+0,90$ \\
& $\begin{array}{l}\text { 1c. El contenido de las informaciones } \\
\text { presentadas en los links es apropiado } \\
\text { para los usuarios. }\end{array}$ & 4,25 & $+0,15$ \\
& $\begin{array}{l}\text { 1d. Las informaciones acrescentarão } \\
\text { conocimiento. }\end{array}$ & 4,75 & $+0,65$ \\
1e. Las informaciones están libres de & & \\
errores gramaticales. & 4,50 & $+0,40$ \\
\hline
\end{tabular}




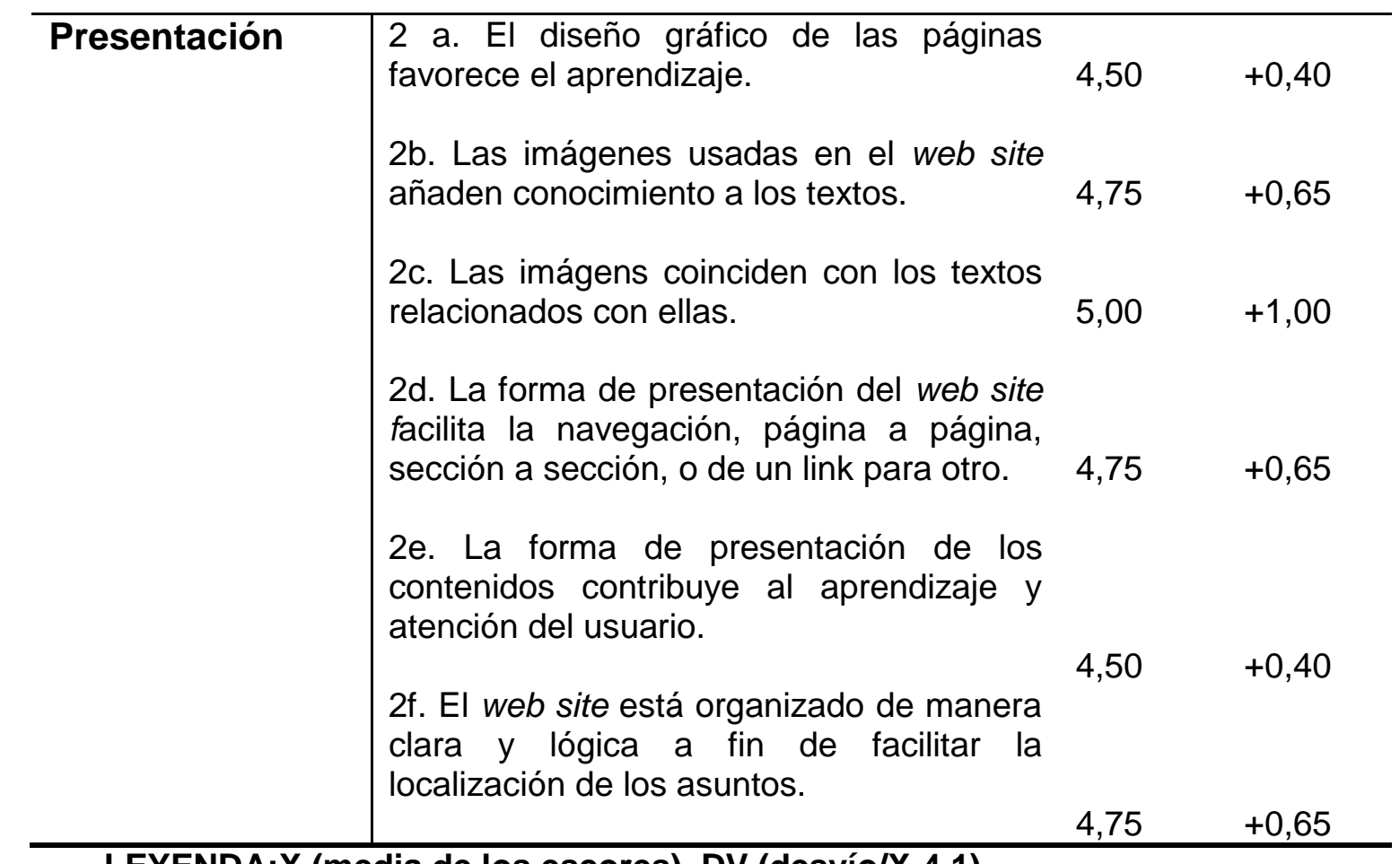

\section{Validación de los pacientes}

Los datos de la validación hecha por los cuatro pacientes con insuficiencia cardiaca que frecuentan o grupo Corazón Fuerte/HUAP/UFF (grupo II) están relacionados con la funcionalidad del Web site, con los criterios de facilidad de navegación y presentación, entendimiento, informaciones e imágenes. El resultado de las evaluaciones de los pacientes presentó el escore medio de $44,25(98,33 \%)$ de los 45 esperados. Por tanto, clasifica el web site como bien elaborado y alcanzó los objetivos propuestos.

Gráfico II. Evaluaciones de los pacientes (Grupo II)

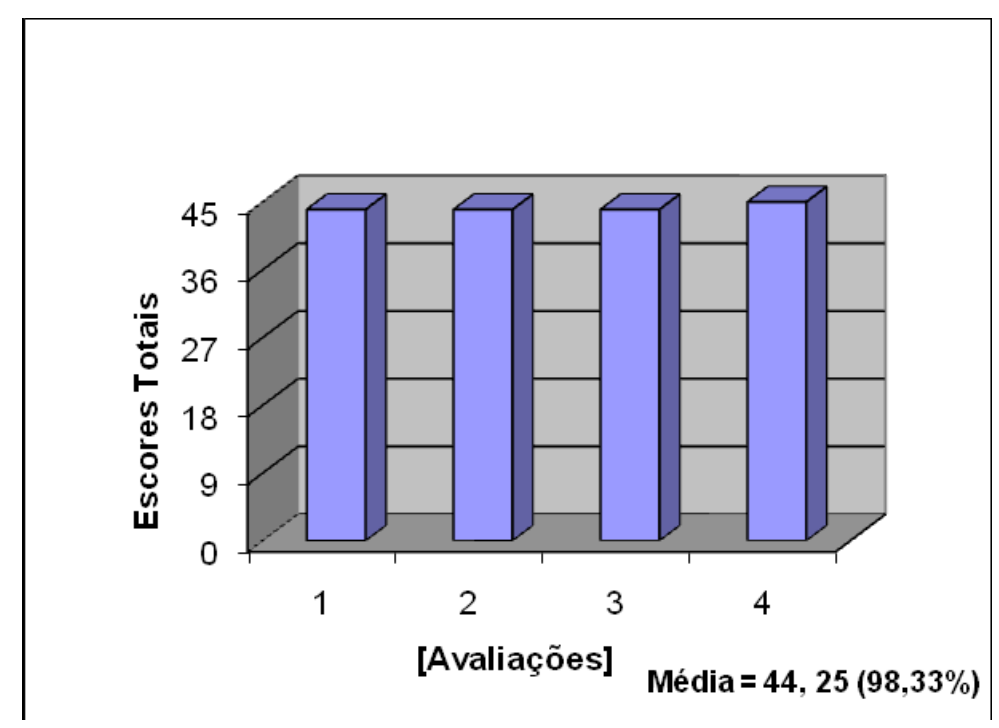


Previamente, se estipuló el Límite de Seguridad (LS) de $0.82(45=1)$ del total de puntos obtenidos en el escore total (Et) como la base para la aprobación del Web site, siendo el valor $L S E t=37$, el mínimo tolerable. La media de los escores totales alcanzó valores superiores al LSEt, un resultado que clasificó el Web site como bien elaborado y que alcanza los objetivos propuestos, o establecidos para la validación.

En el análisis de cada escore de los items de los criterios, se estipuló un valor mínimo esperado, utilizándose para ello la misma estrategia que la del análisis de los resultados de los escores totales obtenidos. En ese análisis, el escore máximo fue de cinco (5) puntos, si se hubiese alcanzado en todos los 9 items supondría el escore total de 45 puntos. El LS (0.82) representa, entonces, el valor 4,1. Esto significó que en cada item, el valor medio esperado de las evaluaciones debería estar por encima de este valor, estipulado como el límite de seguridad del escore por item (LSEi). Una completa discriminación de los escores medios por item y de los desvíos en relación al LSEi, está presentada en la Tabla III.

Tabla III. Escores medios de los items de la validación de los pacientes y los desvíos del Límite de Seguridad (LSEi=4,1).

\begin{tabular}{|c|c|c|c|}
\hline Criterios & Items & $X$ & $D v$ \\
\hline Contenido & $\begin{array}{l}\text { 1a. La homepage (página inicial) es } \\
\text { atractiva e induce al usuario a navegar } \\
\text { por las demá páginas del site. } \\
\text { 1b. La homepage (página inicial) es } \\
\text { suficientemente capaz de ser } \\
\text { manipulada con éxito por usuarios } \\
\text { comunes. } \\
\text { 1c. Las informaciones están } \\
\text { claramente indicadas y organizadas a } \\
\text { fin de ser entendidas por los usuarios. } \\
\text { 1d. Las informaciones añadieron } \\
\text { conocimiento sobre insuficiencia } \\
\text { cardiaca. }\end{array}$ & 4,25 & $+0,15$ \\
\hline Apresentação & $\begin{array}{l}\text { 2a. Las imágenes usadas en el web } \\
\text { site están claramente presentadas. } \\
\text { 2b. Las imágenes mejoran el } \\
\text { entendimiento del texto. } \\
\text { 2c. La forma de presentación del web } \\
\text { site facilita la navegación, página a } \\
\text { página, sección a sección, o de un link } \\
\text { para otro. } \\
\text { 2d. La forma de presentación de los } \\
\text { contenidos contribuye al aprendizaje y } \\
\text { atención del usuario. }\end{array}$ & 5,00 & $\begin{array}{l}+1,00 \\
+1,00\end{array}$ \\
\hline
\end{tabular}


2e. El web site está organizado de manera clara y lógica a fin de facilitar la localización de los asuntos

$5,00+1,00$

LEYENDA:X (media de los escores), DV (desvío/X-4,0).

A partir de las sugerencias de los peritos y de los pacientes, tras la validación, el web site fue modificado y corregido. Abajo la Figura 01 muestra la página inicial del site:

FIGURA 01 - Página inicial del web site

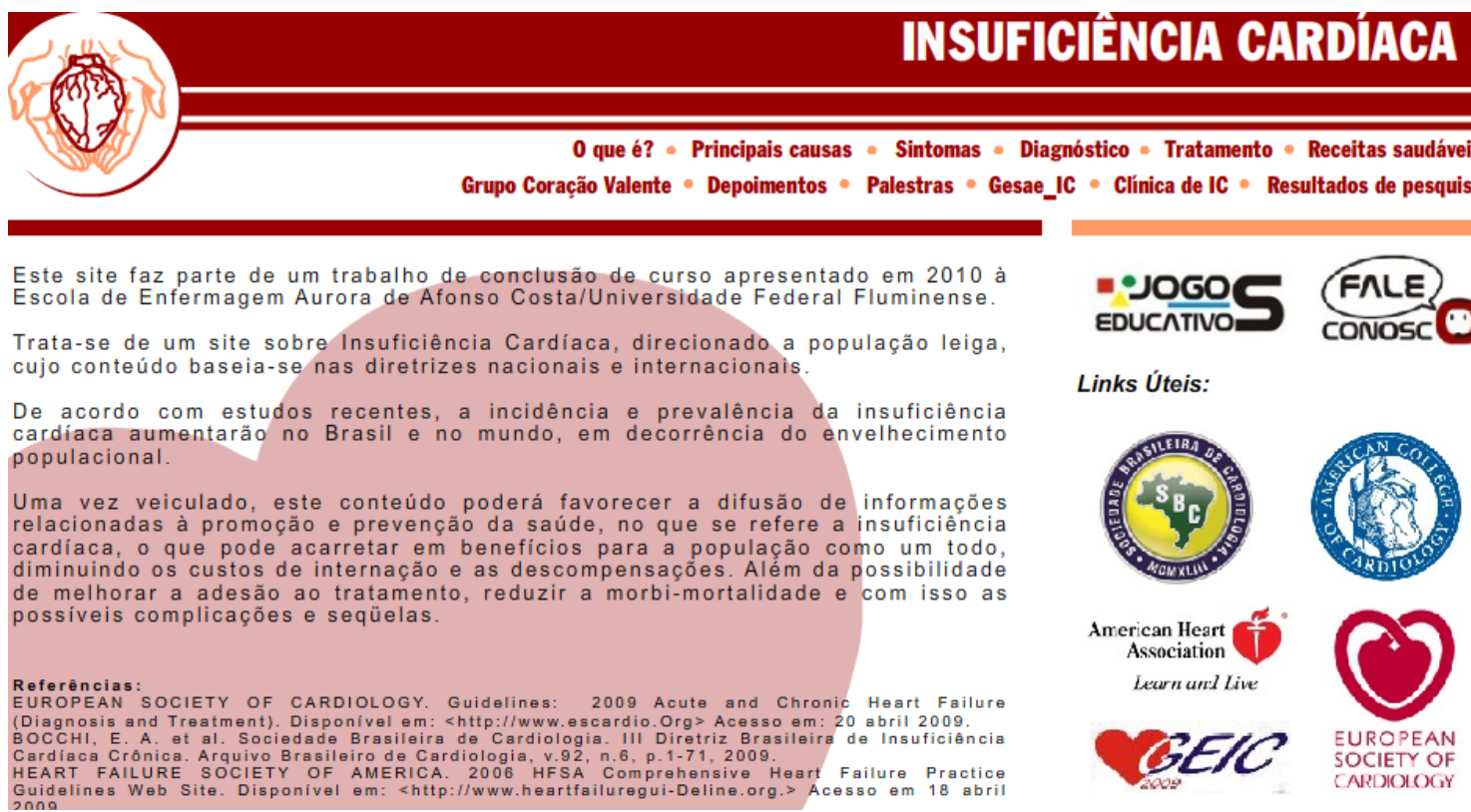

\section{CONCLUSIÓN}

Varios estudios abordan diversos escenarios y estrategias para la educación del paciente con insuficiencia cardiaca. Sin embargo, pocos describen estrategias alternativas y discuten los resultados, principalmente en Brasil.

Por tanto, este estudio se mostró relevante para proponer una alternativa de intervención a través de la creación del web site, que disponibiliza informaciones sobre la Insuficiencia Cardiaca para personas legas. También por la originalidad, porque hasta el momento, no hay en Brasil, en las bases consultadas, sites educativos específicos para el paciente con Insuficiencia Cardiaca. La validación fue otro aspecto importante para garantizar credibilidad y confiabilidad del contenido. Posteriormente, cuando el web site fuera liberado para el usuario, se deben utilizar medidas de supervisión y actualización para mantener la calidad del contenido.

Esta herramienta puede contribuir a mejorar el conocimiento de los pacientes con insuficiencia cardiaca y la adhesión al tratamiento, en la medida que amplía la flexibilización en el aprendizaje, a través de un lenguaje accesible a la población lega, imágenes ilustrativas, juegos educativos e interacción con el usuario para responder a eventuales dudas o sugerencias. 
El web site podrá ser utilizado como un recurso complementario en los grupos de apoyo de pacientes con insuficiencia cardiaca, a través del abordaje de los módulos en las reuniones, en las Clínicas de IC y en visitas domiciliarias.

\section{REFERENCIAS}

1.Marin, HF, Cunha, ICKO. Perspectivas atuais da informática em enfermagem. Revista Brasileira de Enfermagem, São Paulo, v. 59, n.3, p.354-7, maio/jun. 2006.

2. Marques, IR, Marin, HF. Enfermagem na WEB: o processo de criação e validação de um Web site sobre doença arterial coronariana. Revista Latino-Americana de Enfermagem, Ribeirão Preto, v. 10, n. 3, p.298-307, jun, 2002.

3. Dyniewicz, AM. Metodologia da Pesquisa em Saúde para Iniciantes. São Caetano do Sul, São Paulo: Editora Difusão, 2007.

4. Leopardi, MT et al. Metodologia da Pesquisa na Saúde. Santa Maria: Pallotti, 2001.

5. Couto, M. Insuficiência Cardíaca. Universidade Federal de Santa Catarina, 2005. Disponível em: <http://www.hu.ufsc.br/ cardiologia/icc.pdf. Acesso em 15 abril 2009. 